\section{Porcine dentin matrix protein 1: gene structure, cDNA sequence, and expression in teeth}

\author{
Kim J-W, Yamakoshi $Y$, Iwata T, Hu YY, Zhang H, Hu JC-C, Simmer JP. Porcine dentin \\ matrix protein 1: gene structure, cDNA sequence, and expression in teeth. Eur J Oral Sci \\ 2006; 114: 33-41. (C) 2006 The Authors. Journal compilation (c) 2006 Eur J Oral Sci
}

Dentin matrix protein 1 (DMP1) is an acidic non-collagenous protein that is necessary for the proper biomineralization of bone, cartilage, cementum, dentin, and enamel. Dentin matrix protein 1 is highly phosphorylated and potentially glycosylated, but there is no experimental data identifying which specific amino acids are modified. For the purpose of facilitating the characterization of DMP1 from pig, which has the advantage of large developing teeth for obtaining protein in quantity and extensive structural information concerning other tooth matrix proteins, we characterized the porcine DMP1 cDNA and gene structure, raised anti-peptide immunoglobulins that are specific for porcine DMP1, and detected DMP1 protein in porcine tooth extracts and histological sections. Porcine DMP1 has 510 amino acids, including a 16-amino acid signal peptide. The deduced molecular weight of the secreted, unmodified protein is $53.5 \mathrm{kDa}$. The protein has 93 serines and 12 threonines in the appropriate context for phosphorylation, and four asparagines in a context suitable for glycosylation. Dentin matrix protein 1 protein bands with apparent molecular weights between 30 and $45 \mathrm{kDa}$ were observed in partially purified dentin extracts. In developing teeth, immunohistochemistry localized DMP1 in odontoblasts and the dentinal tubules of mineralized dentin and in ameloblasts, but not in the enamel matrix.

\author{
Jung-Wook Kim ${ }^{1,2}$, Yasuo \\ Yamakoshi ${ }^{1}$, Takanori Iwata ${ }^{1,3}$, Yuan \\ Yuan $\mathrm{Hu}^{1}$, Hengmin Zhang ${ }^{1}$, Jan \\ C.-C. $\mathrm{Hu}^{1}$, James P. Simmer ${ }^{1}$ \\ ${ }^{1}$ University of Michigan Dental Research \\ Laboratory, Ann Arbor, MI, USA; ${ }^{2}$ Seoul \\ National University, College of Dentistry \& \\ Dental Research Institute, Department of \\ Pediatric Dentistry, Seoul, Korea; ${ }^{3}$ Tokyo \\ Medical and Dental University, Department of \\ Hard Tissue Engineering, Division of \\ Periodontology, Tokyo, Japan
}

James P. Simmer, University of Michigan Dental Research Laboratory, 1210 Eisenhower Place, Ann Arbor, MI 48108, USA

Telefax: +1-734-9759329.

E-mail: jsimmer@umich.edu

Key words: dentin matrix protein; dentin; DMP1; extracellular matrix; teeth

Accepted for publication November 2005
The formation of tooth dentin occurs in an extracellular space, the content of which is largely determined by odontoblasts. This layer of cells controls parameters relevant to biomineralization: the influx of calcium and phosphate ions; maintenance of the extracellular $\mathrm{pH}$ and ionic strength; and the synthesis and secretion of collagen and non-collagenous phosphoproteins, glycoproteins, proteoglycans, and proteases that work together to generate and mineralize the extracellular space that becomes the body of the tooth (1).

Collagen constitutes $\approx 90 \%$ of the organic matrix of dentin (2). The non-collagenous proteins of dentin are typically anionic proteins that are capable of interacting strongly with calcium phosphates $(2,3)$. The anionic character of the non-collagenous proteins in dentin is derived from an abundance of acidic amino acid residues and post-translational modifications, including phosphorylation, glycosylation, and glycosaminoglycan attachments (4). The interaction of anionic proteins with calcium phosphates can vary, depending upon whether they are free in solution, where they may inhibit mineral induction and growth, or whether they are immobilized on a surface such as collagen, where they can promote mineral induction and growth (5).

The first non-collagenous anionic protein in the dentin matrix to have its deduced amino acid sequence identified through the cloning and characterization of its
cDNA sequence, was dentin matrix protein 1 (DMP1) (6). Dentin matrix protein 1 appears to play a role in the formation of all mineralized tissues $(7,8)$. Understanding how DMP1 contributes to dentin formation is an important part of discerning the molecular mechanisms of dentin biomineralization. Dentin matrix protein 1, however, is a low-abundance protein and is difficult to characterize. Dentin matrix protein 1 is believed to have extensive post-translational modifications. Rat DMP1, for instance, has been shown to have about 53 phosphates per molecule, but no phosphorylated residue has yet been identified (9). Rat DMP1 has three asparagines in the appropriate context for glycosylation, but glycosylation has never been determined experimentally, regardless of whether or not DMP1 is glycosylated (4). Dentin matrix protein 1 is also processed by proteases. Rat bone DMP1 is cleaved into an N-terminal 37-kDa polypeptide and a C-terminal 57-kDa polypeptide (9).

Without better information concerning DMP1 posttranslational modifications, it is difficult to assess the relevance of functional studies employing unmodified recombinant DMP1 expressed in Escherichia coli. While recombinant mouse DMP1 has an apparent molecular mass of $110 \mathrm{kDa}$, the protein extracted from mouse incisors and brain tissues migrates between 130 and $150 \mathrm{kDa}$ on sodium dodecyl sulphate-polyacrylamide gel electrophoresis (SDS-PAGE) (10). Rat bone DMP1 
runs as a doublet at $150 \mathrm{kDa}$, while rat dentin DMP1 can have an apparent molecular mass as high as $200 \mathrm{kDa}$. It is evident that better structural characterization is necessary before meaningful structure/function relationships can be established for DMP1.

Pigs have large developing teeth, which offer obvious advantages for the biochemical characterization of lowabundance proteins such as DMP1. Furthermore, the pig model has the advantage of having a large body of information concerning the biochemical structures and properties of other enamel (11-13) and dentin $(14,15)$ proteins. In this study we expand the investigation of DMP1 to the pig animal model. We report the isolation and characterization of the porcine DMP1 cDNA, the DMP1 gene structure and deduced amino acid sequence, and generate porcine DMP1 anti-peptide immunoglobulins that specifically detect DMP1 protein in protein extracts and histological sections of developing teeth. These data are analyzed in the light of what has been learned about DMP1 from other organisms.

\section{Material and methods}

All experimental procedures involving the use of animals were reviewed and approved by the Institutional Animal Care and Use Program at the University of Michigan.

\section{Cloning of porcine DMP1 cDNA (method 1)}

RNA from porcine dental pulp tissue was isolated by using the RNeasy Protect Maxi kit and protocol (Invitrogen, La Jolla, CA, USA), and converted to cDNA by reverse transcription. The human (16), bovine (17), and mouse (18) DMP1 cDNA sequences were aligned to identify regions of maximum homology. Degenerate primers (pDMP1tF1, 5'-AGYGGAGATGACACCTTTGG; and pDMP1tR1, 5'-CTGCCRCCTCCCACCC) were synthesized and used to amplify a segment of porcine DMP1 cDNA by polymerase chain reaction (PCR) using Platinum Taq DNA polymerase High Fidelity (Invitrogen). The PCR conditions used a 5-min denaturation at $94^{\circ} \mathrm{C}$, followed by 40 cycles each of denaturation at $94^{\circ} \mathrm{C}$ for $30 \mathrm{~s}$, primer annealing at $55^{\circ} \mathrm{C}$ for $30 \mathrm{~s}$, and product extension at $72^{\circ} \mathrm{C}$ for $30 \mathrm{~s}$, with a final extension at $72^{\circ} \mathrm{C}$ for $7 \mathrm{~min}$. The amplification product was ligated into pCR2.1-TOPO (Invitrogen) and transfected into E. coli. DNA minipreps of the recombinant plasmid containing the 257-bp insert were characterized by DNA sequencing using ABI Big Dye Terminator chemistry and an ABI 3100 automated DNA sequencer at the University of Michigan's DNA Sequencing Core. This sequence was analyzed, and porcine DMP1-specific oligonucleotide primers were designed for rapid amplification of cDNA ends (RACE). The DMP1-specific primers used for 5'-RACE were pDMP1RACE5R (5'-GCCTGCTGTCCACCTCATCCTCGT) and pDMP1RACE5R1 (5'-GGCCCCTGCTCTCACTGGTGGTATC). The 3'-RACE primers were pDMP1RACE3F (5'-GTGGCCCAGGACCTGAAGAGAGCA) and pDMP1RACE3F1 (5'-GGGGAAGTCAGTGCCCAAGATACCA). The RACE was accomplished using the BD SMART RACE CDNA Amplification Kit (BD Bioscience Clontech, San Jose, CA, USA). The 5'- and 3'-RACE products were ligated into pCR2.1-TOPO (Invitrogen) and transfected into E. coli.

\section{Cloning full-length porcine DMP1 cDNA (method 2)}

RNA was isolated from dental mesenchyme using TRIzol (Invitrogen) reagent and converted to cDNA in three separate experiments using Superscript ${ }^{\mathrm{TM}}$ reverse transcriptase (Invitrogen). Each cDNA preparation was amplified in three separate PCR reactions (nine reactions in total) using Accu Pfx Polymerase SuperMix (Invitrogen) and the primerpair 5'-CAGCTATGAAGACCAGCATCC and 5'-CTAGTAGCCGTCCTGGCAGT. The PCR conditions used a 5 -min denaturation at $95^{\circ} \mathrm{C}$, followed by 35 cycles each of denaturation at $95^{\circ} \mathrm{C}$ for $15 \mathrm{~s}$, primer annealing at $60^{\circ} \mathrm{C}$ for $30 \mathrm{~s}$, and product extension at $68^{\circ} \mathrm{C}$ for $105 \mathrm{~s}$, with a final extension at $68^{\circ} \mathrm{C}$ for $7 \mathrm{~min}$. To minimize potential errors caused by infidelity in the PCR and reverse transcription (RT) reactions, three DMP1 cDNAs from each reaction (27 PCR products) were characterized by direct DNA sequencing using the two PCR oligonucleotides and two internal oligonucleotides (5'-TGTCCTGTGCTCTCCCAGT and 5'-TCGCCCAAGGTGTCATCTCC) as primers. Direct DNA sequencing of amplified porcine genomic DNA verified the entire porcine DMP1 cDNA sequence. The oligonucleotides and PCR conditions are provided in Table 1 .

\section{Determination of intron-exon boundaries}

Primers were designed from each exon after sequence comparison with human, mouse, and bovine DMP1. Using the porcine genomic DNA as a template, DMP1 genomic segments were amplified using Platinum Taq DNA polymerase High Fidelity (Invitrogen), cloned and characterized by DNA sequencing. The oligonucleotide primer pairs and PCR conditions are shown in Table 1.

\section{Genome walking}

Genomic sequences outside the $5^{\prime}$ and $3^{\prime}$ ends of the porcine DMP1 gene were obtained using the DNA Walking SpeedUp premix kit (Seegene, Seoul, Korea) and protocol. For the $5^{\prime}$ end, oligonucleotides pDMP1TSP6 (5'-CAGTGGTCTTAGCATCTCCT) and pDMP1TSP5 (5'-CTGGCTCTACTGAAGTCACA), and for the $3^{\prime}$ end, oligonucleotides pDMP1TSPF4 (5'-ACATGGTGAGACTAGAAGC) and pDMP1TSP F2 (5'-GCACAGTGAGGTGTGTTGGATTAG), were used according to the protocol.

\section{Sequence analyses}

The signal peptide cleavage site was predicted using Signal $\mathrm{P}$ 3.0 (19) at the Center for Biological Sequence Analysis Website (http://www.cbs.dtu.dk/services/SignalP/). The molecular weight and isoelectric point of porcine DMP1 was predicted using the Compute $\mathrm{pI} / \mathrm{Mw}$ tool (http:// c.expasy.org/tools/pi_tool.html) on the Expasy molecular biology server (http://expasy.cbr.nrc.ca/tools/scnpsit1.html) at the Swiss Institute of Bioinformatics. Searches for potential phosphorylation, and $\mathrm{O}$ - and N-linked glycosylation sites were performed at the Center for Biological Sequence Analysis at the Technical University of Denmark Website (http://www.cbs.dtu.dk/) using the NetNGlyc 1.0 (20), NetOGlyc 2.0 (21), and NetPhos 2.0 (22) prediction servers. Percentage identities of DMP amino acid sequences from porcine, human, bovine, and mouse were calculated 
Table 1

Oligonucleotide primers for dentin matrix protein 1 (DMP1) gene characterization

\begin{tabular}{|c|c|c|c|c|}
\hline Name & & Anneal & $\begin{array}{l}\text { Extension } \\
\text { temperature }\end{array}$ & $\begin{array}{l}\text { Extension } \\
\text { time }\end{array}$ \\
\hline \multicolumn{5}{|c|}{ A. Primers used to amplify porcine DMP1 genomic sequences } \\
\hline pDMP1gF1 & 5'-ATCCACACGAGAGTGGCTTC & $60^{\circ} \mathrm{C}$ & $68^{\circ} \mathrm{C}$ & $5 \mathrm{~min}$ \\
\hline pDMP1gR1 & $5^{\prime}$-TGGGAGAGCACAGGACAAC & & & \\
\hline pDMP1gF2 & 5'-GAGGTGACGTATCCAGCTATGA & $60^{\circ} \mathrm{C}$ & $68^{\circ} \mathrm{C}$ & $3 \mathrm{~min}$ \\
\hline pDMP1gR2 & 5'-CAAAGGTGGTGCTGGTGTC & & & \\
\hline pDMP1gF3 & 5'-GTCAGTTGGCTCAGACACCA & $60^{\circ} \mathrm{C}$ & $68^{\circ} \mathrm{C}$ & $3 \mathrm{~min}$ \\
\hline pDMP1gR3 & 5'-ТTTТССТССАСТСАСАGCAA & & & \\
\hline \multicolumn{5}{|c|}{ B. Primers used for direct PCR sequencing of the porcine $D M P 1$ gene } \\
\hline pDMP1x1F & 5'AGTGTGGGTGTCCTGGAGTC & $55^{\circ} \mathrm{C}$ & $72^{\circ} \mathrm{C}$ & $30 \mathrm{~s}$ \\
\hline pDMP1x1R & 5'-TTTTCCAAACCACACAGCAG & & & \\
\hline pDMP1x23F & 5'-TCAGTTGACGGACTTTTGGA & $55^{\circ} \mathrm{C}$ & $72^{\circ} \mathrm{C}$ & $45 \mathrm{~s}$ \\
\hline pDMP1x23R & 5'-CATTTGCAGTGAAGCCAGTG & & & \\
\hline pDMP1x $45 \mathrm{~F}$ & 5'-AGAGATTTGGGTCACCATGC & $55^{\circ} \mathrm{C}$ & $72^{\circ} \mathrm{C}$ & $30 \mathrm{~s}$ \\
\hline pDMP1x45R & 5'-GCCGGGGAATCTAATCTAGC & & & \\
\hline pDMP1x45R1 & 5'-TGGCCTAAGAGGCTGAGAAG & & & \\
\hline pDMP1x6F & 5'-GGGCCTTAGGTAGTGCCTTC & $55^{\circ} \mathrm{C}$ & $72^{\circ} \mathrm{C}$ & $30 \mathrm{~s}$ \\
\hline pDMP1x6R & 5'-GTCCACCTCATCCTCGTTGT & & & \\
\hline pDMP1g6F1 & 5'-AGTGCCCAAGATACCACCAG & $60^{\circ} \mathrm{C}$ & $68^{\circ} \mathrm{C}$ & $60 \mathrm{~s}$ \\
\hline pDMP1g6R1 & 5'-ACTTGAGGTTGGCAGTGCTT & & & \\
\hline pDMP1g6F2 & 5'-CAGAGTCCACGGAAGAGGAG & $60^{\circ} \mathrm{C}$ & $68^{\circ} \mathrm{C}$ & $60 \mathrm{~s}$ \\
\hline pDMP1g6R2 & 5'-TTGATTTGCTGCTGTCTTGG & & & \\
\hline pDMP1g6F3 & 5'-CACGAACACTGACTCCCAGA & $55^{\circ} \mathrm{C}$ & $72^{\circ} \mathrm{C}$ & $30 \mathrm{~s}$ \\
\hline pDMP1x6cR & 5'-СTTCTGTTTAATGGGAGGAAAG & & & \\
\hline
\end{tabular}

PCR, polymerase chain reaction.

from pairwise aligments using SIM (at http://www.expasy. org/tools/sim-prot.html).

\section{Preparation of porcine tooth powder and extraction of DMP1}

Tooth germs of permanent molars were surgically extracted from the maxillae and mandibles of 6-month-old pigs at the Michigan State University Meat Laboratory (East Lansing, MI, USA), as described previously (14). Soft tissue was removed and the hard tissue was quickly frozen in dry ice. Secretory stage dental enamel was removed by scraping with a curette. The remaining hard tissue was reduced to a powder using a jaw crusher (Retsch, Newtown, PA, USA). All extraction steps were carried out at $4^{\circ} \mathrm{C}$ or on ice. Protease Inhibitor Cocktail Set III (1 mM 4-[Aminoethyl]benzenesulfonyl fluoxide hydrochloride [AEBSF], $0.8 \mu \mathrm{M}$ aprotinin, $50 \mu \mathrm{M}$ bestatin, $15 \mu \mathrm{M}$ E-64, $20 \mu \mathrm{M}$ leupeptin and $10 \mu \mathrm{M}$ pepstatin) (EMD Biosciences, San Diego, CA, USA) and $1 \mathrm{mM} \mathrm{1,10-phenanthroline} \mathrm{(Sigma,}$ St Louis, MO, USA) were added into the buffer during the extraction. Dentin powder was sequentially extracted with $50 \mathrm{mM}$ Tris- $\mathrm{HCl} / 4 \mathrm{M}$ guanidine buffer $(\mathrm{pH} 7.4)$, then with $50 \mathrm{mM}$ Tris- $\mathrm{HCl} / 4 \mathrm{M}$ guanidine $/ 0.5 \mathrm{M}$ EDTA buffer (pH 7.4). These extracts were centrifuged at $7000 \mathrm{~g}$, desalted and concentrated using the combination of a Spectra/Por 3 membrane (Spectrum Laboratories, Rancho Dominguez, CA, USA) with a YM-3 membrane (Amicon, Beverly, MA, USA), and were lyophilized and stored at $-80^{\circ} \mathrm{C}$.

\section{Partial purification of porcine DMP1}

The following fractionation of dentin proteins was carried out as previously described (14). In brief, the lyophilized
EDTA extract was dissolved in $10 \mathrm{ml}$ of $50 \mathrm{mM}$ Tris- $\mathrm{HCl} /$ $6 \mathrm{M}$ urea buffer ( $\mathrm{pH} 7.4$ ) and fractionated by anionexchange chromatography using a Q-Sepharose Fast Flow column $(1.6 \mathrm{~cm} \times 20 \mathrm{~cm}$; GE Healthcare Biosciences, Little Chalfont, Bucks., UK). Dentin matrix protein 1 eluted in the third peak (Q3), which was concentrated with a YM-3 membrane and further fractionated over a hydroxyapatite (HA) column. The HA column divided Q3 into three parts. The contents of the second peak $(\mathrm{H} 2)$ were fractionated by size-exclusion chromatography on a Superdex 200 column (1.6 cm $\times 60 \mathrm{~cm}$; GE Healthcare Biosciences). Dentin matrix protein 1-positive bands were identified among the contents of the second chromatographic peak (S2). Samples from the guanidine supernatant, guanidine pellet, the guanidine/EDTA extracts and S2 were incubated with Protein G-Sepharose (GE Healthcare Biosciences) and centrifuged to remove immunoglobulins.

\section{Antibody production}

A 14-amino acid segment (Gln173-Asp186; Cys-QEEGVGEPRGDNPD) from the porcine DMP1 deduced amino acid sequence was selected based upon overall antigenic index, favorable secondary structure, peptide location, and cross-species reactivity. The peptide was conjugated to the carrier peptide-KLH (keyhole limpet hemocyanin). Antibodies were generated in rabbits using a 2-month protocol that included three immunizations, one test bleed, a fourth immunization, and a final bleed. Specific anti-DMP1 immunoglobulin was purified from the final bleed using an affinity column containing the immobilized unconjugated DMP1 peptide, and tested using enzyme-linked immunosorbent assay (ELISA) before being used for western blotting and immunohistochemistry. 


\section{Sodium dodecyl sulphate-polyacrylamide gel electrophoresis}

Sodium dodecyl sulphate-polyacrylamide gel electrophoresis was performed using PAGEr Gold Precast Gels (4-20\% gradient, $10 \%$ or $7.5 \%$ Tris-Glycine gels) (Cambrex Bio Science, Rockland, ME, USA). Samples were dissolved in Laemmli sample buffer (Bio-Rad, Hercules, CA, USA) and electrophoresis was carried out using a current of $20 \mathrm{~mA}$ for $1.5 \mathrm{~h}$. The gels were stained with Bio-Safe Coomassie (BioRad) or Stains-all (Sigma). The apparent molecular weights of protein bands were estimated by comparison with SeeBlue Plus2 Pre-Stained Standard (Invitrogen).

\section{Western immunoblots}

After SDS-PAGE, proteins were electrotransferred onto a Hybond-P membrane (GE Healthcare Biosciences). Porcine DMP1 antibodies were used at dilution of $1: 50,000$. The membrane was immunostained by chemiluminescent detection with the ECL Advance Western Blotting Detection Kit (Amersham Pharmacia, Piscataway, NJ, USA).

\section{Preparation of tissues for immunostaining}

Developing second molars of 6-month-old pigs were fixed, demineralized, and embedded in paraffin. In brief, fixation was in $4 \%$ paraformaldehyde/DEPC at $4^{\circ} \mathrm{C}$ for $2 \mathrm{~d}$. The fixed teeth were demineralized for 3 wk using 10\% EDTA/ diethylpyrocarbonate (DEPC) at $\mathrm{pH}$ 7.4. Histology processing used washes at $4^{\circ} \mathrm{C}$ in phosphate-buffered saline (PBS) (pH 7.4) for 6-8 h, 70\% (v/v) ethanol overnight, 95\% (v/v) ethanol the second day, $100 \%$ (v/v) ethanol overnight, and xylene for $2 \mathrm{~h}$ at room temperature, followed by embedding by paraffin perfusion for 3-4 h. The molars were embedded with the mesial surface down and sectioned at 6- $\mu \mathrm{m}$ thickness.

\section{Immunohistochemistry}

The AEC rabbit primary staining kit (Zymed, San Francisco, CA, USA) was used. Rabbit anti-porcine amelogenin immunoglobulin was used as a positive control and the negative control was rabbit immunoglobulin $\mathrm{G}(\operatorname{IgG})$ at a dilution of $1: 100$. To enhance antigen-antibody binding and reduce non-specific reaction, an antigen retrieval procedure was conducted prior to immunohistochemistry (IHC) experiments (23). The affinity-purified porcine DMP1 antibodies were dissolved at a concentration of $1 \mathrm{mg} \mathrm{ml}^{-1}$ and used at a dilution of $1: 100$. Tissue sections were analyzed and photographed using a Nikon Eclipse Microscope and Act1 software (Mager Scientific, Dexter, MI, USA).

\section{Results}

The full-length porcine dentin matrix acidic phosphoprotein (DMP1) cDNA (2681 bp) was cloned and characterized, and its amino acid sequence was deduced (Fig. 1). The pig protein has 494 amino acids following the removal of a 16-amino acid signal peptide. The deduced molecular weight of the secreted protein is $53.5 \mathrm{kDa}$, although the actual molecular weight is likely to be much larger owing to post-translational modifications. Porcine DMP1 has 99 serines $(20 \%), 93$ of which

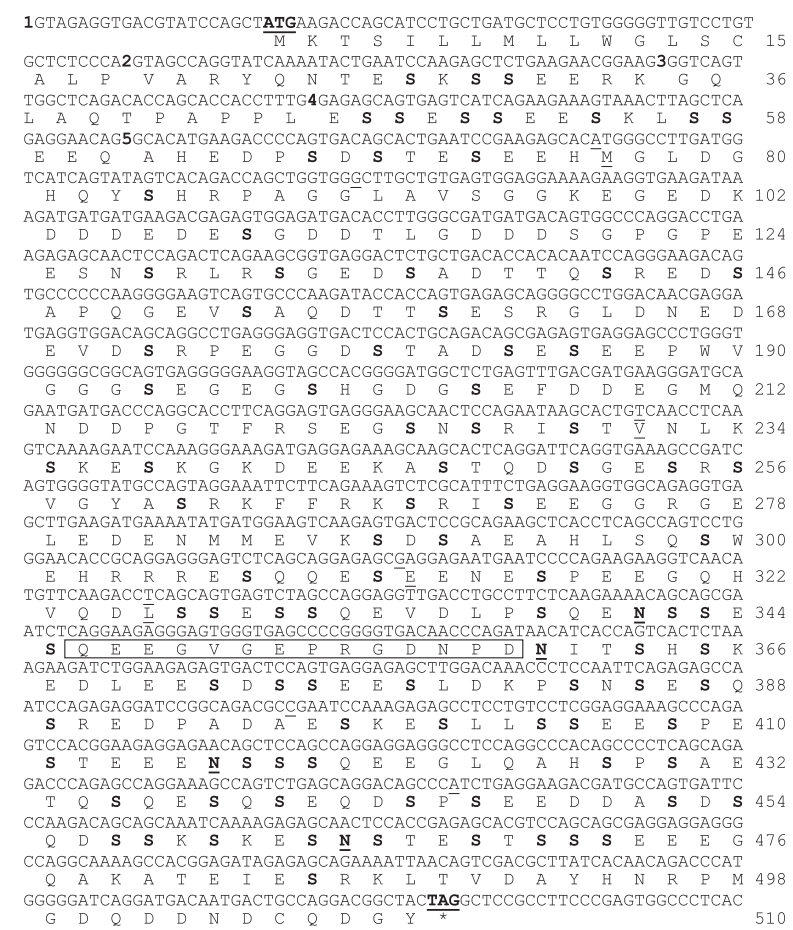

Fig. 1. Analysis of porcine dentin matrix protein 1 (DMP1) cDNA and deduced amino acid sequences. The porcine DMP1 coding region from exons 2 to 6 are shown. On the right are the numbers of the last amino acid in each row. In the nucleotide rows, numbers in bold indicate the positions of introns in the porcine Dmpl gene. The Signal $\mathrm{P}$ predicted signal peptide cleavage site is after Ala16, suggesting that Leu17 is at the $\mathrm{N}$ terminus of the secreted protein. NetNGlyc identified four asparagines (shown in bold and underlined) in the appropriate context for glycosylation: Asn341, Asn360, Asn416, and Asn464, with Asn360 being in the most favorable context. NetPhos indicated that 93 out of 99 serines (bold) and 12 of 19 threonines (not shown) are in the appropriate contexts for phosphorylation. The amino acid segment used to raise DMP1 antibodies in rabbit is boxed. The translation initiation (ATG) and termination (TAG) codons are in bold and underlined. The positions of the five introns in porcine $\mathrm{Dmp} 1$ are indicated by numbers within the nucleotide sequence. Seven nucleotide polymorphisms were identified, four of which changed the deduced amino acid sequence: Met76Leu, Val231Ala, Glu312Lys, and Leu326Pro (underlined, not bold).

are in the appropriate context for phosphorylation. Its amino acid composition is also notable because of its many acidic residues [89 (or 18\%) glutamic acids; 51 (or $10.3 \%$ ) aspartic acids]. Overall, negatively charged side chains outnumber positively charged groups by 140 to 42, giving the protein an acidic calculated isoelectric point of 4.1. Porcine DMP1 also has four asparagines in the appropriate context for glycosylation (Asn341, Asn360, Asn416, and Asn464).

To confirm the cDNA sequence and to determine the positions of intervening sequences in the porcine DMP1 gene, we characterized the DMP1 coding region and intron/exon borders by direct sequencing of porcine genomic DNA (Tables 2 and 3). The sequences at the intron/exon borders are shown in Table 3. Full-length porcine DMP1 cDNAs were independently cloned and 
Table 2

Porcine dentin matrix protein 1 (DMP1) gene structure

\begin{tabular}{lcccc}
\hline Exon & Length bp & Coding bp & Intron & Length \\
\hline 1 & 104 & 0 & 1 & $\approx 6 \mathrm{~kb}$ \\
2 & 75 & 54 & 2 & $475 \mathrm{bp}$ \\
3 & 48 & 48 & 3 & $\approx 2.7 \mathrm{~kb}$ \\
4 & 33 & 33 & 4 & $189 \mathrm{bp}$ \\
5 & 48 & 48 & 5 & $\approx 2.6 \mathrm{~kb}$ \\
6 & 2,373 & 1,347 & & \\
\hline
\end{tabular}

five nucleotide polymorphisms were identified, four of which changed the deduced amino acid sequence (Met76Leu, Leu90Leu, Val231Ala, Glu312Lys, and Leu326Pro). This indicates that DMP1 protein sequences vary within species.

The porcine DMP1 deduced amino acid sequence was aligned to human (16), bovine (17), and mouse (18) DMP1 sequences (Fig. 2). Among the 93 serines appropriate for phosphorylation, 72 were found to be conserved in all four DMP1 sequences. Asn464 is the only potentially glycosylated asparagine that is conserved in all four DMP1s. The predicted integrin-binding site (RGD) is conserved in all of the four known mammalian DMP1 sequences. Pairwise alignments of the four DMP1 sequences gave the following percentage identities: porcine-human, $67 \%$; porcine-bovine, $73 \%$; porcine-murine, $62 \%$; human-bovine, $70 \%$; human-murine $64 \%$; and bovine-murine $64 \%$.

We prepared an anti-peptide immunoglobulin against the conserved segment of porcine DMP1 containing the RGD integrin-binding motif (QEEGVGEPRGDNPD), which contained no residues that were predicted to be post-translationally modified. The affinity-purified antipeptide immunoglobulin was used to detect DMP1 in porcine dentin extracts (Fig. 3). Dentin matrix protein 1 was detected as four bands, which are presumably cleavage products, migrating between 30 and $45 \mathrm{kDa}$ on SDS-PAGE. In rat, DMP1 cleavage products at 37 and $57 \mathrm{kDa}$ have been characterized (9). Full-length recombinant DMP1 protein, which lacks post-translational modifications, migrates at $110 \mathrm{kDa}(10)$. Negative controls demonstrated the necessity of removing naturally occurring immunoglobulins from dentin extracts prior to performing western blot analyses. We did not detect larger immunopositive bands following the removal of contaminating immunoglobulins The largest DMP1 immunopositive bands in western blots of bovine and

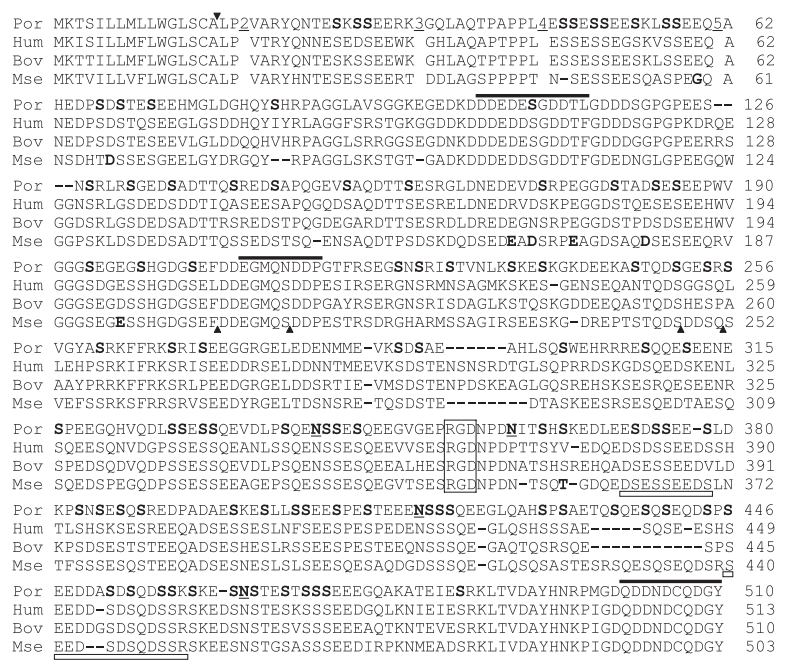

Fig. 2. Analysis of aligned dentin matrix protein 1 (DMP1) sequences. The deduced porcine DMP1 amino acid sequence (Por; Sus scrofa; acc. no.: AY963261) was aligned with the homologous sequences Hum (human; Homo sapiens; acc. no.: U89012), Bov (bovine; Bos taurusk; acc. no.: U47636), and Mse (mouse; Mus musculus; acc. no.: U65020). The number of the last amino acid in each row is indicated on the right. All of the introns in the porcine Dmpl gene are phase 0, that is, they occur between codons. The numbers and positions of the four porcine Dmpl introns (2 to 5) interrupting coding segments are indicated by the underlined numbers in the first row. Most of the DMP1 protein is encoded by exon 6 . The 93 serines in porcine DMP1 that are in the appropriate context for phosphorylation are in bold. The four asparagines in porcine DMP1 that are potentially glycosylated are in bold and underlined. The conserved RGD integrin-binding site is boxed. A solid bar above the alignment marks the three peptide segments conserved in all known DMP1 sequences, inclusive of birds. Hollow bars below the alignment mark segments of recombinant rat DMP1 that bound collagen (41). A downward pointing arrowhead in the first row indicates the signal peptide cleavage site. Four putative cleavage sites assigned from studies of rat DMP1 extracted from bone are indicated by upward pointing arrowheads below the alignment in row 4.

mouse dentin are at $150 \mathrm{kDa}(10)$, while a band as high as $200 \mathrm{kDa}$ was detected in rat (24). As in studies of other organisms, the quantity of DMP1 in dentin extracts was very low. Future studies of porcine DMP1 will need to be scaled up significantly to determine whether DMP1 components having higher molecular weights are present.

The porcine DMP1 anti-peptide immunoglobulin was used to detect the presence of DMP1 protein in

Table 3

Porcine dentin matrix protein 1 (DMP1) exon/intron boundaries

\begin{tabular}{lcc}
\hline Ex/In/Ex & Exon & Intron \\
\hline $1 / 1 / 2$ & GAACTGAAGAGG/GTAAGACATTTT...CTTTCCCCACAG/GTAGAGGTGACG \\
$2 / 2 / 3$ & TGTGCTCTCCCA/GTAAGTATCAGG...TAAATTTCTAG/GTAGCCAGGTAT \\
$3 / 3 / 4$ & GAAGAACGGAAG/GTAAGTAGAAAT...TCCTTTCACAG/GGTCAGTTGGCT \\
$4 / 4 / 5$ & GCACCACCTTTG/GTAACTACCTTA...TTTTCTTTTTAG/GAGAGCAGTGAG \\
$5 / 6 / 6$ & TCAGAGGAACAG/GTAATTAAGCCG...CCCAAACTCCAG/GCACATGAAGAC
\end{tabular}



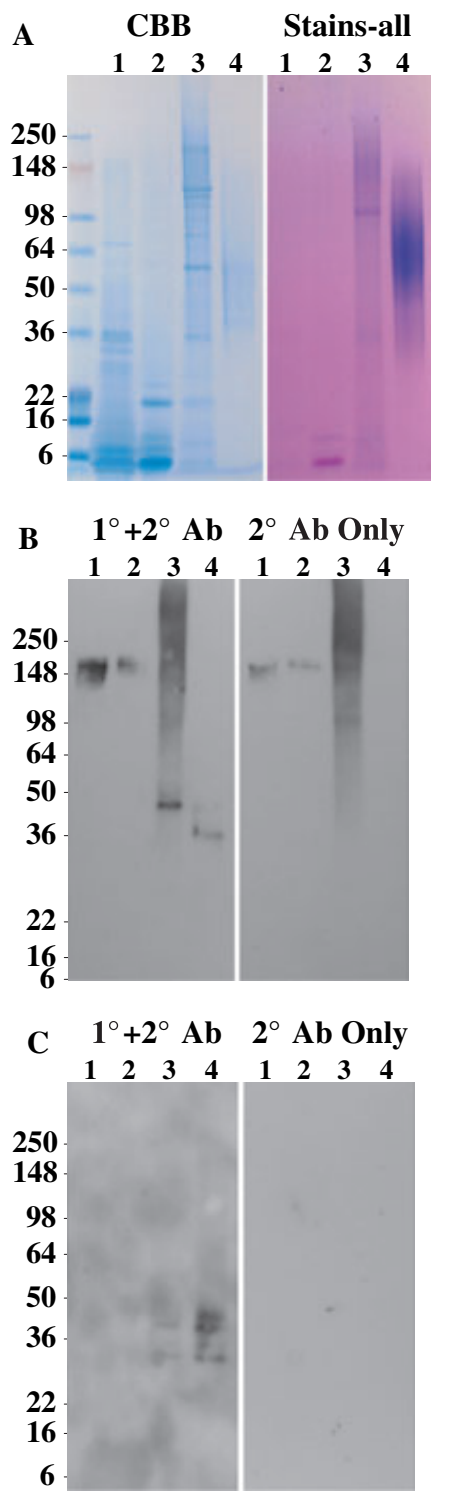

Fig. 3. Detection of dentin matrix protein 1 (DMP1) in porcine dentin extracts. Selected fractions in the extraction of DMP1 from developing porcine molars are shown on 4-20\% gradient sodium dodecyl sulphate-polyacrylamide gels (A) stained with Coomassie Brilliant Blue (CBB, left) and Stains-all (right) and by western blot analyses (B and C), with (left), and without (right), the porcine DMP1 primary antibody. The four lanes are the guanidine extract supernatant (lane 1), the guanidine extract pellet (lane 2), the guanidine/EDTA extract (lane 3) and the final DMP1-containing fraction that was partially purified from the guanidine/EDTA extract by ion exchange, hydroxyapatite affinity, and size exclusion chromatography (lane 4). The initial western blot analysis of replica gels of those shown in (A) had multiple positive bands in the negative control using only the secondary antibody (B), presumably as a result of the presence of porcine immunoglobulins in the dentin extracts. All fractions were then cleared of immunoglobulins using a protein $G$ affinity column, which eliminated the positive reactions associated with the $2^{\circ}$ antibody (C). Four DMP1-positive bands were identified as having apparent molecular weights ranging from 30 to $45 \mathrm{kDa}$ (lane 4), in a fraction that contained a Stains-all positive smear that was most intense between 45 and $100 \mathrm{kDa}$. $1^{\circ} \mathrm{Ab}$ is the DMP1 antibody produced in this study. $2^{\circ} \mathrm{Ab}$ is a goat-anti-rabbit antibody. developing pig molars (Fig. 4). Dentin matrix protein 1-immunopositive signals were observed in secretorystage ameloblasts, especially at their proximal ends near the stratum intermedium, in odontoblasts, and in the dentinal tubules of mineralized dentin. No positive signal was observed in forming predentin, or in the nuclear compartments of any cells. The strength of the positive reaction was not intense and was sensitive to the experimental conditions used.

\section{Discussion}

Dentin matrix acidic phosphoprotein 1 was originally discovered by deducing the amino acid sequence of a rat cDNA that was obtained by screening a Lambda cDNA library with polyclonal antibodies raised against a mixture of dentin phosphoproteins (6). This was the first cDNA to be characterized that encoded a dentinspecific acidic phosphoprotein. Shortly after this discovery, it was determined that the gene encoding human DMP1 localizes to a region on chromosome $4 \mathrm{q} 12-\mathrm{q} 21$ that is linked to dentinogenesis imperfecta (DGI) $(25,26)$.

Subsequent studies have determined that DMP1 is not dentin specific, but is expressed in bone (27), in mineralized tissues in general (28), and even in nonmineralized tissues (including liver, muscle, brain, pancreas, and kidney) (10). Dmpl knockout mice displayed no dental phenotype in the heterozygous condition $(+/-)$ or in the homozygous condition $(-/-)$ in embryos and newborns. After birth, defects were observed in the maturation of predentin to dentin, which was associated with increased accumulation (but not expression) of biglycan in the expanded predentin, and a general reduction in the expression of dentin sialophosphoprotein (DSPP) (7). Other mineralized tissues, such as bone, enamel, and cementum, were affected and third molars were either missing or retarded in some Dmpl null mice. Severe defects in cartilage formation were also observed (8).

Because DMP1 functions in many tissues, genetic defects in human $D M P 1$ probably do not contribute to the etiology of inherited defects of dentin, such as DGI and dentin dysplasia (DD), as these phenotypes are restricted to dentin specifically. Mutations in the $D M P 1$ coding region have been ruled out in some kindreds with DGI (16), while an increasing number of $D S P P$ mutations have been associated with inherited defects of dentin (29-34).

The $D M P 1$ gene appears to evolve rapidly in vertebrates. The various porcine DMP1 cDNAs we characterized showed five variations among their deduced amino acid sequences. The DMPI coding sequence from exon 6 , which comprises all but the first 60 codons, has been determined for a broad range of mammalian species, including monotremes (platypus) and marsupials (wallaby and opossum) (35), as well as from 19 species of bat (36). DMP1 sequences have also been determined for reptiles (caiman) (37) and birds (chicken and pheasant) (38). Alignments of all known DMP1 sequences identi- 

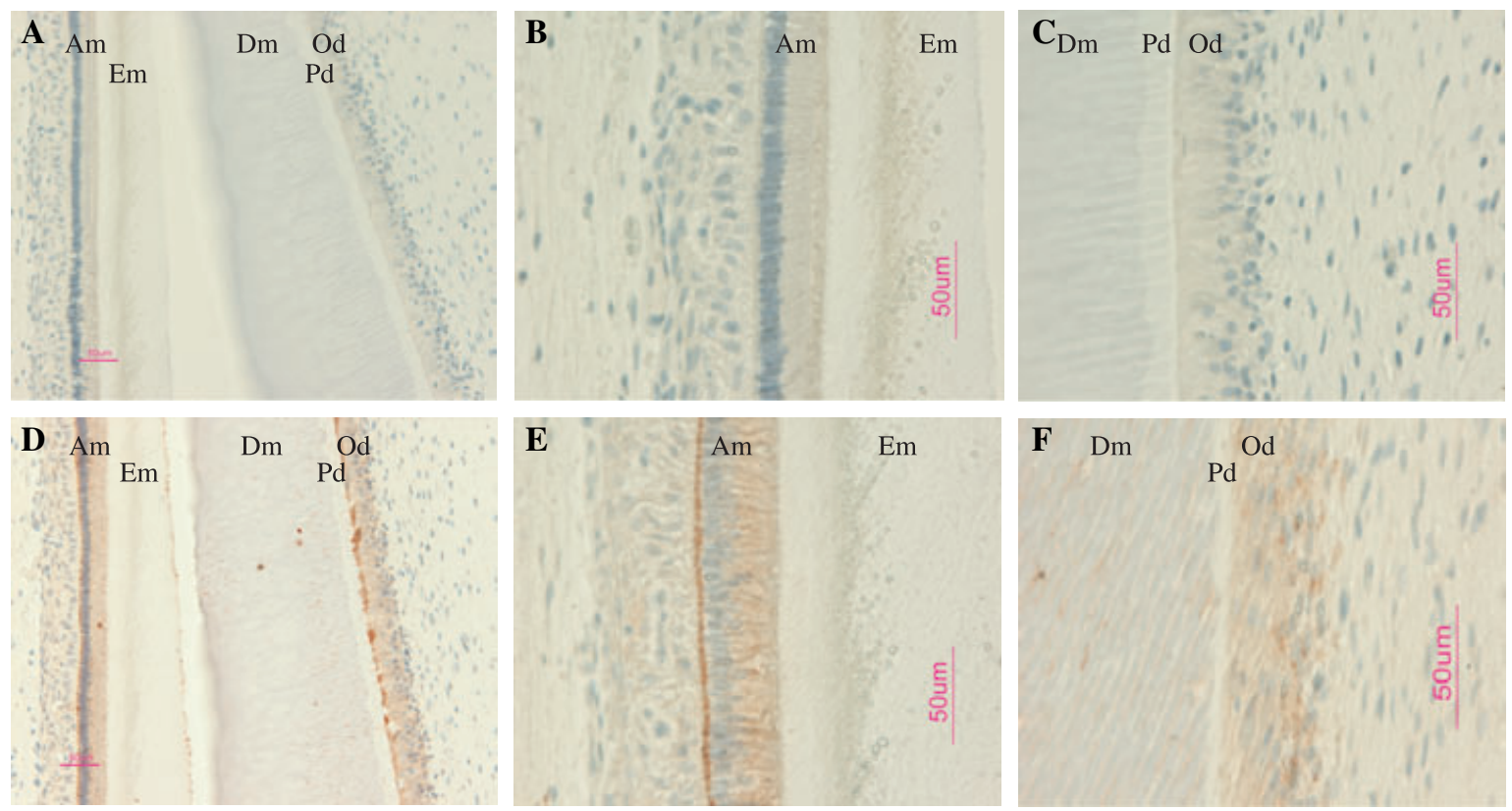

Fig. 4. Immunodetection of dentin matrix protein 1 (DMP1) in developing porcine molars. All sections (A-F) are of developing molars from 6-month-old pigs at the secretory stage of amelogenesis. The top row (A-C) shows negative controls in which preimmune serum was used instead of the affinity-purified DMP1 antibody. The sections on the left (A, D) are lower-magnification views showing the spatial relationship between ameloblasts (left) and odontoblasts (right). The bottom row (D-F) shows equivalent sections using the DMP1 antibody. Ameloblasts (Am) were immunopositive, as were odontoblasts (Od) and the dentinal tubules of the mineralized dentin matrix $(\mathrm{Dm})$. Predentin $(\mathrm{Pd})$ and the enamel matrix $(\mathrm{Em})$ were negative.

fied three short conserved segments of the DMP1 primary structure (38). According to the numbering for porcine DMP1, these conserved areas are Asp104Leu114, Glu209-Pro216, and Asp502-Tyr510. The universal importance of these DMP1 segments is unknown. The RGD sequence associated with integrin binding is conserved in all mammalian species, but is absent from all non-mammalian DMP1 sequences characterized to date.

Dentin matrix protein 1 is proposed to be a SIBLING (small integrin-binding ligand $\mathrm{N}$-linked glycoprotein). The five proteins in this family each have an integrinbinding motif and conserved phosphorylation and $\mathrm{N}$-glycosylation sites, and have proposed roles as activators of specific matrix metalloproteinase 'partners', with DMP1 activating proMMP-3 (39). Although the function of DMP1 is not known, its functional properties are likely to be influenced by its post-translational modifications. For instance, with respect to the ability of DMP1 to nucleate hydroxyapatite formation, the nonphosphorylated recombinant protein acted as an HA nucleator, whereas the same protein phosphorylated in vitro had no detectable effect on HA formation and growth (40). Non-phosphorylated, recombinant rat DMP1 bound collagen, but the three DMP1 segments implicated in collagen binding (DSESSEEDR, SEENR, and DSDSQDSSR) (41) are all predicted to be phosphorylated (underlined), suggesting that the native DMP1 protein may not show the same tendency to bind collagen.

It has been proposed that non-phosphorylated DMP1 is taken up into the nucleus, where it acts as a tran- scription factor that drives the differentiation of precursor cells into osteoblasts. Having accomplished this, DMP1 is proposed to be phosphorylated by a nuclear kinase and transported out of the cell where it nucleates HA formation (42). Such a scenario raises issues as to how the DMP1 signal peptide is cleaved and how the protein might be glycosylated without passing through the endoplasmic reticulum. The post-translational modifications of DMP1 may vary in different tissues. Rat bone DMP1 differs in apparent molecular weight from rat dentin DMP1 (24).

We tested our porcine DMP1 anti-peptide immunoglobulin in western blot and immunohistochemical analyses (Figs 3 and 4). The antibody gave a positive and specific signal on western blots of dentin extracts, but only after immunoglobulins were removed from the protein samples. We suspect that contaminating immunoglobulins may partially explain the detection of DMP1-positive bands of various sizes in different tissues $(10,24)$. In the rat, two excellent studies have combined in situ hybridization and immunohistochemistry to clarify the expression of DMP1 during tooth formation at multiple developmental stages $(43,44)$. Both of these studies identified DMP1 in dentinal tubules, which is consistent with our findings in pig. We also observed a DMP1 signal in secretory ameloblasts, but not in dental enamel, and we could not detect DMP1 protein in enamel extracts by western blot analyses (data not shown). Dentin matrix protein 1 was not immunodetected in ameloblasts in the rat studies, so our positive DMP1 immunostaining of porcine ameloblasts requires confirmation by other methods. 
By opening the investigation of DMP1 in the porcine animal model, we hope to facilitate studies that will allow us to characterize the structural features of DMP1 so that we can better understand its functional properties. Characterization of the porcine cDNA sequence and gene structure has allowed us to deduce the porcine DMP1 primary structure, assess its potential for posttranslational modifications, develop DMP1-specific antibodies, and identify DMP1 in tooth extracts and in histological sections of porcine molars. These studies will facilitate the isolation of DMP1 from porcine teeth to advance our understanding of its structural features and the mechanisms of its functional roles in tooth development and mineralization.

Acknowledgements - We thank Mr Tom Forton, Manager of the Michigan State University Meat Laboratory and members of the Michigan State University Department of Animal Science for their kind assistance in obtaining fresh developing molars from pigs slaughtered at their facility. We thank Dr Robert H. Lyons, director of the University of Michigan's DNA Sequencing Core. We thank Zymed Laboratories (San Francisco, CA, USA) for generation of the rabbit anti-peptide immunoglobulin against porcine DMP1. This investigation was supported by USPHS Research Grants DE12769, DE15846, and DE11301 from the National Institute of Dental and Craniofacial Research, National Institutes of Health, Bethesda, MD 29892.

\section{References}

1. Lundquist P, Ritchie HH, Moore K, Lundgren T, Linde A. Phosphate and calcium uptake by rat odontoblast-like MRPC1 cells concomitant with mineralization. $J$ Bone Miner Res 2002; 17: 1801-1813.

2. LINDE A. Dentin matrix proteins: composition and possible functions in calcification. Anat Rec 1989; 224: 154-166.

3. Boskey AL. The role of extracellular matrix components in dentin mineralization. Crit Rev Oral Biol Med 1991; 2: 369-387.

4. Qin C, BABA O, Butler WT. Post-translational modifications of sibling proteins and their roles in osteogenesis and dentinogenesis. Crit Rev Oral Biol Med 2004; 15: 126-136.

5. Linde A, Lussi A, Crenshaw MA. Mineral induction by immobilized polyanionic proteins. Calcif Tissue Int 1989; 44: 286-295.

6. George A, Sabsay B, Simonian PA, Veis A. Characterization of a novel dentin matrix acidic phosphoprotein. Implications for induction of biomineralization. J Biol Chem 1993; 268: 12624-12630.

7. Ye L, MacDougall M, Zhang S, Xie Y, Zhang J, Li Z, Lu Y, Mishina Y, Feng JQ. Deletion of dentin matrix protein-1 leads to a partial failure of maturation of predentin into dentin, hypomineralization, and expanded cavities of pulp and root canal during postnatal tooth development. J Biol Chem 2004; 279: 19141-19148.

8. Ye L, Mishina Y, Chen D, Huang H, Dallas Sl, Dallas M, Kunieda TW, Tsutsui T, Boskey A, Bonewald LF, Feng JQ. Dentin matrix protein 1 (Dmpl) deficient mice display severe defects in cartilage formation responsible for a chondrodysplasia-like phenotype. J Biol Chem 2004; 280: 61976203.

9. Qin C, Brunn JC, Cook RG, Orkiszewsi RS, Malone JP, VeIs A, ButLER WT. Evidence for the proteolytic processing of dentin matrix protein 1. Identification and characterization of processed fragments and cleavage sites. J Biol Chem 2003; 278: 34700-34708.

10. Terasawa M, Shimokawa R, Terashima T, Ohya K, Takagi $\mathrm{Y}$, Shimokawa H. Expression of dentin matrix protein 1
(DMP1) in nonmineralized tissues. J Bone Miner Metab 2004; 22: $430-438$.

11. Fincham AG, Moradian-Oldak J, Simmer JP. The structural biology of the developing dental enamel matrix. J Struct Biol 1999; 126: 270-299.

12. Hu JC-C, Yamakoshi Y. Enamelin and autosomal-dominant amelogenesis imperfecta. Crit Rev Oral Biol Med 2003; 14: 387398.

13. Yamakoshi Y, Hu JC-C, Ryu OH, Tanabe T, Oida S, Fukae M, Simmer JP. A comprehensive strategy for purifying pig enamel proteins. In: Kobayashi I Ozawa H, eds. Biomineralization: formation, diversity, evolution and application. Hadano: Tokai University Press, 2004; 326-332.

14. Yamakoshi Y, Hu JC, Fukae M, Iwata T, Kim JW, Zhang H, SimMER JP. Porcine dentin sialoprotein is a proteoglycan with glycosaminoglycan chains containing chondroitin 6-sulfate. J Biol Chem 2005; 280: 1552-1560.

15. Yamakoshi Y, Hu JC-C, Fukae M, Zhang H, Simmer JP. Dentin glycoprotein: The protein in the middle of the dentin sialophosphoprotein chimera. J Biol Chem 2005; 280: $17472-$ 17479 .

16. Hirst KL, Simmons D, Feng J, Aplin H, Dixon MJ, MacDougall M. Elucidation of the sequence and the genomic organization of the human dentin matrix acidic phosphoprotein 1 (DMP1) gene: exclusion of the locus from a causative role in the pathogenesis of dentinogenesis imperfecta type II. Genomics 1997; 42: 38-45.

17. Hirst KL, Ibaraki OCK, Young MF, Dixon MJ. Cloning and expression analysis of the bovine dentin matrix acidic phosphoprotein gene. J Dent Res 1997; 76: 754-760.

18. MacDougall M, Gu TT, Luan X, Simmons D, Chen J. Identification of a novel isoform of mouse dentin matrix protein 1: spatial expression in mineralized tissues. $J$ Bone Miner Res 1998; 13: 422-431.

19. Bendtsen JD, Nielsen H, Von Heijne G, Brunak S. Improved prediction of signal peptides: SignalP 3.0. J Mol Biol 2004; 340: 783-795.

20. Blom N, Sicheritz-Ponten T, Gupta R, Gammeltoft S, BRUNAK S. Prediction of post-translational glycosylation and phosphorylation of proteins from the amino acid sequence. Proteomics 2004; 4: 1633-1649.

21. Hansen Je, Lund O, Tolstrup N, Gooley AA, Williams KL, BRUNAK S. NetOglyc: prediction of mucin type O-glycosylation sites based on sequence context and surface accessibility. Glycoconj J 1998; 15: 115-130.

22. Blom N, Gammeltoft S, Brunak S. Sequence and structurebased prediction of eukaryotic protein phosphorylation sites. J Mol Biol 1999; 294: 1351-1362.

23. Shi SR, Key ME, Kalra KL. Antigen retrieval in formalinfixed, paraffin-embedded tissues: an enhancement method for immunohistochemical staining based on microwave oven heating of tissue sections. J Histochem Cytochem 1991; 39: 741748.

24. Qin C, Brunn JC, Jones J, George A, Ramachandran A, GORSKI JP, BUTLER WT. A comparative study of sialic acid-rich proteins in rat bone and dentin. Eur J Oral Sci 2001; 109: 133141.

25. George A, Gui J, Jenkins NA, Gilbert DJ, Copeland NG, VEIS A. In situ localization and chromosomal mapping of the AG1 (Dmp1) gene. J Histochem Cytochem 1994; 42: 15271531.

26. Aplin HM, Hirst KL, Crosby AH, Dixon MJ. Mapping of the human dentin matrix acidic phosphoprotein gene (DMP1) to the dentinogenesis imperfecta type II critical region at chromosome 4q21. Genomics 1995; 30: 347-349.

27. D'Souza RN, Cavender A, Sunavala G, Alvarez J, Ohshima T, Kulkarni AB, MacDougall M. Gene expression patterns of murine dentin matrix protein 1 (Dmpl) and dentin sialophosphoprotein (DSPP) suggest distinct developmental functions in vivo. J Bone Miner Res 1997; 12: 20402049.

28. Feng JQ, Huang H, Lu YYeL, Xie Y, Tsutsui TW, Kunieda T, Castranio T, Scott G, Bonewald LB, Mishina Y. The Dentin matrix protein 1 (Dmp1) is specifically expressed in 
mineralized, but not soft, tissues during development. $J$ Dent Res 2003; 82: 776-780.

29. Xiao S, Yu C, Chou X, Yuan W, Wang Y, Bu L, Fu G, Qian M, Yang J, Shi Y, Hu L, Han B, Wang Z, Huang W, Liu J, Chen Z, Zhao G, Kong X. Dentinogenesis imperfecta 1 with or without progressive hearing loss is associated with distinct mutations in DSPP. Nat Genet 2001; 27: 201-204.

30. Zhang X, Zhao J, Li C, Gao S, Qiu C, Liu P, Wu G, Qiang B, Lo WH, SHEN Y. DSPP mutation in dentinogenesis imperfecta Shields type II. Nat Genet 2001; 27: 151-152.

31. Rajpar MH, Koch MJ, Davies RM, Mellody KT, Kielty CM, Dixon MJ. Mutation of the signal peptide region of the bicistronic gene DSPP affects translocation to the endoplasmic reticulum and results in defective dentine biomineralization. Hum Mol Genet 2002; 11: 2559-2565.

32. Kim JW, Hu JC, Lee JI, Moon SK, Kim YJ, Jang KT, Lee SH, Kim CC, Hahn SH, Simmer JP. Mutational hot spot in the DSPP gene causing dentinogenesis imperfecta type II. Hum Genet 2005; 116: 186-191.

33. Kim JW, Nam SH, Jang KT, LeE SH, Kim CC, Hahn SH, Hu JC, SIMMER JP. A novel splice acceptor mutation in the DSPP gene causing dentinogenesis imperfecta type II. Hum Genet 2004; 115: 248-254.

34. Dong J, Gu T, Jeffords L, MacDougall M. Dentin phosphoprotein compound mutation in dentin sialophosphoprotein causes dentinogenesis imperfecta type III. Am J Med Genet A 2005; 132: 305-309.

35. Toyosawa S, O'Huigin C, Klein J. The dentin matrix protein 1 gene of prototherian and metatherian mammals. $J$ Mol Evol 1999; 48: 160-167.

36. Van Den Bussche Ra, Reeder SA, Hansen EW, Hoofer SR. Utility of the dentin matrix protein 1 (DMP1) gene for resol- ving mammalian intraordinal phylogenetic relationships. Mol Phylogenet Evol 2003; 26: 89-101.

37. Toyosawa S, O"'Huigin C, Tichy H, Klein J. Characterization of dentin matrix protein 1 gene in crocodilia. Gene 1999; 234: 307-314.

38. Toyosawa S, Sato A, O"Huigin C, Tichy H, Klein J. Expression of the dentin matrix protein 1 gene in birds. $J \mathrm{Mol}$ Evol 2000; 50: 31-38.

39. Ogbureke KU, Fisher LW. Expression of SiblinGs and their partner MMPs in salivary glands. J Dent Res 2004; 83: 664-670.

40. Tartaix PH, Doulaverakis M, George A, Fisher LW, Butler WT, Qin C, Salih E, Tan M, Fujimoto Y, Spevak L, Boskey AL. In vitro effects of dentin matrix protein-1 on hydroxyapatite formation provide insights into in vivo functions. J Biol Chem 2004; 279: 18115-18120.

41. He G, George A. Dentin matrix protein 1 immobilized on type I collagen fibrils facilitates apatite deposition in vitro. $J$ Biol Chem 2004; 279: 11649-11656.

42. Narayanan K, Ramachandran A, Hao J, He G, Park KW, Cho M, George A. Dual functional roles of dentin matrix protein 1. Implications in biomineralization and gene transcription by activation of intracellular $\mathrm{Ca}^{2+}$ store. $\mathrm{J} \mathrm{Biol} \mathrm{Chem}$ 2003; 278: 17500-17508.

43. Baba O, Qin C, Brunn JC, Wygant JN, McIntyre BW, BUTLER WT. Colocalization of dentin matrix protein 1 and dentin sialoprotein at late stages of rat molar development. Matrix Biol 2004; 23: 371-379.

44. Toyosawa S, Okabayashi K, Komori T, IJuhin N. mRNA expression and protein localization of dentin matrix protein 1 during dental root formation. Bone 2004; 34: 124-133. 